\title{
Procedimentos manifestos por alunos em atividades de modelagem matemática: compreensões à luz da análise de conteúdo
}

\begin{abstract}
RESUMO
Neste trabalho, trazemos para discussão os procedimentos manifestos por alunos de um $8^{\circ}$ ano do Ensino Fundamental ao desenvolverem atividades de modelagem matemática. Para discutir acerca desses procedimentos, apresentamos alguns episódios que retratam a dinâmica do envolvimento deles com atividades de modelagem e nos apoiamos na Análise de Conteúdo, proposta por Laurence Bardin. Da análise identificamos cinco categorias de procedimentos: focalizam a temática em estudo, indicam a organização do trabalho a ser realizado, depõem a escolha de estratégias, revelam o uso ou a compreensão de conceitos matemáticos e denotam processos avaliativos. Concluímos que em atividades de modelagem matemática os procedimentos manifestos pelos alunos não podem ser analisados isoladamente; é o conjunto de procedimentos, que possibilitam o desenvolvimento da atividade de modelagem e que carregam, implícita ou explicitamente; intenções e conhecimentos dos alunos, negociações deles ou entre eles e o professor.
\end{abstract}

PALAVRAS-CHAVE: Atividades de modelagem matemática. Procedimentos dos alunos. Análise de conteúdo. 


\section{INTRODUÇÃO}

A Modelagem Matemática é assumida, nesta investigação, como uma alternativa pedagógica para o processo de ensino e de aprendizagem de Matemática (Almeida; Brito, 2005), que considera o estudo de uma situação, cuja sua origem está, de modo geral, fora da matemática.

Com um encaminhamento que defende que atividades de modelagem matemática são orientadas pela busca de solução para um problema oriundo de determinada situação, consideramos que o desenvolvimento de tais atividades em aulas de Matemática pode favorece com que o aluno tenha um papel ativo, uma vez que exige que ele desenvolva estratégias de resolução, visando responder o problema que pode ter sido suscitado, inclusive, por ele.

O fato de uma atividade de modelagem matemática ter como ponto de partida uma situação, o seu desenvolvimento pressupõe que os alunos, reunidos em grupos, selecionem um problema a ser resolvido; assumam um conjunto de atitudes que permita chegar a uma resposta para tal problema, que pode ser aceita ou não como satisfatória e; realizem uma análise crítica e consciente acerca da resposta obtida. Assim, o desenvolvimento de atividades de modelagem matemática requer inúmeros procedimentos dos alunos, e são para esses procedimentos que direcionamos o nosso olhar.

Visando discutir acerca dos procedimentos manifestos por alunos de $8^{\circ}$ ano do Ensino Fundamental, apresentamos alguns episódios que retratam a dinâmica empreendida por três grupos de alunos ao desenvolverem as atividades de modelagem nominadas: Erva-Mate, tema sugerido pela professora e problema identificado pelos alunos e; Milho e Planetas do Sistema Solar, temas e problemas indicados pelos alunos. Cada uma dessas atividades foi desenvolvida apenas por um grupo de alunos, ou seja, cada grupo se envolveu com apenas uma temática. Para proceder à análise desses episódios, bem como amparar os recortes que fizemos dos diálogos dos alunos, seguimos orientações da Análise de Conteúdo (Bardin, 1977). As inferências e considerações que realizamos têm como base a categorização dos procedimentos que identificamos.

\section{SOBRE O PAPEL DOS ALUNOS EM ATIVIDADES DE MODELAGEM MATEMÁTICA}

Muito embora na literatura seja possível encontrar distintas concepções de Modelagem Matemática no âmbito da Educação Matemática, assumimos neste estudo que ela se constitui em uma alternativa pedagógica (ALMEIDA; BRITO, 2005) na qual conceitos matemáticos e situações externas ao contexto da Matemática se relacionam de forma a promover momentos de debates, viabilizando construção/mobilização de conhecimentos diversos, sobretudo matemáticos.

Em todas as acepções de Modelagem Matemática, nessa perspectiva, é indicado que professor e alunos desempenhem comportamento ativo. Também, que as atividades de modelagem matemática sejam orientadas por temas (situação e/ou problema em estudo) escolhidos pelos alunos, pelo professor ou por um acordo entre ambos (VERONEZ, 2013).

Uma vez que a prática de Modelagem Matemática empreendida por alunos e professor em sala de aula precisa ser assumida por ambos e conduzir a uma 
investigação que visa encontrar uma solução para um problema evidenciado em uma situação qualquer; eles precisam reconhecer seus diferentes papéis no desenvolvimento de atividades de modelagem matemática. Se por um lado os alunos são os sujeitos principais, por outro, o professor é o orientador de todo o processo. Daí a assertiva de que atividades de modelagem matemática, no âmbito da Educação Matemática, "são potencialmente cooperativas" (Castro, 2017, p. 14) e se desenvolvidas com os alunos reunidos em grupos têm possibilidade de fomentar discussões interessantes (Vertuan, 2013; Veronez, 2013), uma vez que, tendo essa organização, os alunos têm oportunidades de refletir, decidir e agir sobre as mais diversas situações e, de desenvolver um olhar crítico para elas, posto que podem analisá-las e compreendê-las a partir de diferentes pontos de vista.

Essas atitudes empreendidas pelos alunos, reunidos em grupos, quando desenvolvem atividades de modelagem matemática podem ser mais ou menos intensas, de acordo com seus conhecimentos sobre o tema ou sobre conceitos matemáticos requeridos na situação em foco (Almeida; Silva; Vertuan, 2013) e, ainda, podem sofrer influências do professor, já que ele deve atuar de forma a orientar caminhos, sugerir possibilidades de investigação, mediar conhecimentos, fomentar o debate e a reflexão.

Assim, aulas regidas por atividades de modelagem matemática tem potencial para favorecer com que os alunos manifestem diversos procedimentos que thes permitam interagir com os colegas e com o professor ao passo que buscam uma solução para o problema em estudo. Esses procedimentos, em sua totalidade, são o que possibilitam o desenvolvimento da atividade de modelagem matemática e que carregam, implícita ou explicitamente; intenções e conhecimentos dos alunos, negociações deles ou entre eles e o professor, bem como modos de pensar e agir.

Com o propósito de discutir acerca dos procedimentos manifestos por alunos de $8^{\circ}$ ano do Ensino Fundamental, ao desenvolverem atividades de modelagem matemática, fizemos algumas opções metodológicas conforme descritas na seção a seguir.

\section{ASPECTOS METODOLÓGICOS DA INVESTIGAÇÃO REALIZADA}

A presente investigação segue orientações da abordagem qualitativa que, conforme Lüdke e André (2007), é aquela que se desenvolve em uma situação natural, rica em dados predominantemente descritivos, tendo caráter aberto e flexível e apresenta como lócus a realidade de forma complexa e contextualizada. Além disso, nesse método de pesquisa os dados são obtidos no contato direto do pesquisador com a situação estudada e devido ao fato de valorizar o processo e não apenas o resultado final, possibilita interpretação por parte do pesquisador.

Nesta investigação consideramos três atividades de modelagem matemática desenvolvidas, no contexto de aulas regulares, por alunos de 8 ano do Ensino Fundamental, com idades entre 13 e 14 anos, de uma escola pública do campo. Cada uma dessas atividades foi desenvolvida por grupos distintos, compostos por três alunos, duas delas tiveram seus temas (Milho e Planeta do Sistema Solar) sugeridos por seus respectivos grupos de alunos e o tema (Erva Mate), que gerou a outra atividade, foi proposto pela professora da turma.

Convém destacar que optamos por trazer as três atividades supracitadas, mesmo os alunos tendo desenvolvido outras, devido ao fato deles se mostrarem 
bastante envolvidos com os temas que as originaram. A atividade do Milho foi escolhida porque o grupo de alunos utilizou uma variedade de recursos para desenvolvê-la e a dos Planetas do Sistema Solar porque havia muita interação entre os alunos do grupo. Já a atividade de modelagem da Erva-Mate foi escolhida por causa da variedade de discussões aventadas pelos alunos que a desenvolveram.

O processo de coleta de dados contou com o uso de gravadores de áudio e de vídeo, além dos materiais que continham registros dos alunos produzidos durante o desenvolvimento das atividades de modelagem matemática. Assim, o material gravado, que fora todo transcrito, bem como todas as produções dos alunos se configura em material de análise. Esses dados coletados forneceram subsídios para identificar, classificar e analisar os procedimentos manifestos pelos alunos e que, serviram como base para compreensão de aspectos que permearam o desenvolvimento de tais atividades.

Para o tratamento dos dados coletados seguimos orientações da Análise de Conteúdo proposta por Bardin (1977), a qual pode ser entendida como

\footnotetext{
um conjunto de técnicas de análise das comunicações, visando obter, por meio de procedimentos sistemáticos, e objetivos de descrição de conteúdo da mensagem, indicadores (quantitativos ou não) que permitam a inferência de conhecimentos relativos às condições de produção/recepção (variáveis inferidas) desta mensagem (BARDIN, 1997, p. 42).
}

Nessa metodologia de análise, segundo a autora, busca-se conhecer aquilo que está por trás das palavras sobre as quais o pesquisador se debruça; busca-se por realidades por meio das mensagens (comunicação). Daí a organização dessa metodologia em três fases: pré-análise, exploração do material e tratamento dos resultados.

A fase pré-análise corresponde ao contato inicial com os materiais coletados e tem como propósito sua síntese e organização. A leitura "flutuante" e a escolha dos documentos são algumas das ações requeridas nesta fase. A leitura "flutuante" corresponde ao conhecimento dos textos e das mensagens neles contidas. Segundo Bardin (1977, p.96), o termo leitura "flutuante" está relacionado ao fato de que "pouco a pouco a leitura vai se tornando mais precisa, em função das hipóteses emergentes, da projeção de teorias adaptadas sobre o material e da possível aplicação de técnicas utilizadas com materiais análogos". De modo geral, nela emergem impressões, representações, emoções, conhecimentos e expectativas. A escolha dos documentos considerados e submetidos ao processo de análise diz respeito à constituição e/ou seleção de um corpus.

$\mathrm{Na}$ presente investigação, na pré-análise, transcrevemos as gravações das aulas em forma de diálogos, assistimos aos vídeos, realizamos a leitura das produções dos alunos e, portanto, selecionamos o material que comporia a análise. Logo, o corpus são os diálogos e os registros dos alunos.

$\mathrm{Na}$ fase de exploração do material, segundo Bardin (1977), o conteúdo dos diálogos é organizado a partir de palavras ou expressões significativas, podendo o investigador estabelecer categorias. As categorias são entendidas como rubricas ou classes que agrupam elementos com características comuns sob um título genérico. Nessa segunda fase, identificamos, no corpus, os procedimentos manifestos pelos alunos ao desenvolverem atividades de modelagem matemática. 
Tais procedimentos, mais tarde, vieram a compor grupos, que levou à identificação de algumas categorias de procedimentos.

$\mathrm{Na}$ fase final, de tratamento dos resultados, foram analisados todos os procedimentos manifestos pelos alunos e realizadas interpretações, análises reflexivas e críticas e também inferências acerca do estudo realizado. Foi nessa fase que as categorias de procedimentos puderam ser compreendidas e discutidas com vistas ao objeto do estudo.

\section{OS PROCEDIMENTOS DOS ALUNOS IDENTIFICADOS NAS ATIVIDADES DE MODELAGEM MATEMÁTICA}

Para tecer considerações acerca dos procedimentos dos alunos trazemos três atividades de modelagem matemática por eles desenvolvidas e aqui denominadas Atividade 1, Atividade 2 e Atividade 3. Os temas que subsidiaram o desenvolvimento dessas atividades são: Erva-Mate, Planetas do Sistema Solar e Milho, respectivamente. $\mathrm{Na}$ análise apresentada discutimos sobre os procedimentos manifestos pelos alunos ao longo da descrição do desenvolvimento dessas atividades de modelagem matemática.

Na descrição das atividades os diálogos, que denotam recortes das principais discussões dos alunos durante o desenvolvimento de cada uma delas, são trazidos em forma de Episódios. Nos diálogos apresentados, visando manter o anonimato dos alunos os denominamos por suas duas primeiras letras do primeiro nome: $\mathrm{Ep}$, Gi e Ca (Atividade 1); Ma, Bi e Na (Atividade 2) e El, Al e Lu (Atividade 3). A fala da professora pesquisadora é indicada pela abreviatura Prof..

A atividade com o tema Erva-Mate, demandou um período de 20 aulas para ser concluída, já as atividades com o tema Planetas do Sistema Solar e Milho, foram desenvolvidas, cada uma, durante 15 aulas.

\section{Atividade 1}

Esta atividade de modelagem matemática teve o tema Erva-Mate proposto pela professora. Para tal proposição foi levada em consideração a região na qual os alunos residem e a familiaridade deles com o tema, uma vez que nessa região há inúmeras propriedades que cultivam a planta e três indústrias que beneficiam Erva-Mate para a comercialização. Outro aspecto é que um considerável número de trabalhadores dessas indústrias são familiares desses alunos.

A partir do tema, conforme orientação da professora, os alunos Ep, Gi e Ca elencaram algumas perguntas que retratam seus interesses em investigar aspectos específicos sobre a Erva-Mate. Tais perguntas, que foram entregues por escrito pelos alunos, constam no Quadro 1. 
Quadro 1 - Perguntas de interesse dos alunos sobre a erva-mate

Perguntas de interesse dos alunos sobre a erva-mate

1) Quanto tempo demora a realizar a colheita da Erva-Mate?

2) Quanto tempo a Erva fica no secador?

3) Qual a distância entre um pé de erva e outro?

4) Qual a diferença entre Erva-Mate para chimarrão fina e grossa?

5) Quais os tamanhos dos pacotes de Erva-Mate vendidos no mercado?

6) Quais os estados que mais consomem Erva-Mate no Brasil?

7) Como é o processo de fabricação de Erva-Mate para chimarrão?

8) Além do chimarrão, no que mais a Erva-Mate é utilizada?

9) Uma arroba de Erva-Mate, depois de processada, renderá quantos quilos de ErvaMate pronta para chimarrão?

10) Até quantos metros uma árvore de Erva-Mate pode atingir de altura?

Fonte: Castro (2017).

As perguntas elencadas pelos alunos, em sua maioria, são perguntas pontuais e, para algumas delas, as respostas já eram conhecidas. Já outras, foram listadas por eles por considerarem que seriam fáceis de responder. Esse procedimento dos alunos de levantar questões objetivas de diversas naturezas, sobre a Erva-Mate, possibilitou que eles mobilizassem conhecimentos prévios e buscassem informações sobre características básicas acerca do tema.

As questões elencadas direcionaram o estudo dos alunos no momento de realizar a busca por respostas por meio de pesquisa na internet e de campo (visita à ervateira). As informações obtidas pelos alunos e a orientação da professora, pode ter contribuído para que, o procedimento agora fosse o de assumir algumas informações como sendo relevantes.

A análise dos dados enfatizados como mais expressivos encaminhou os alunos ao procedimento de escrever novas questões. Ao olhar para as informações que possuíam e reconhecer algumas como significativas, os alunos formularam novos problemas e direcionaram seus estudos.

A pergunta formulada pelos alunos, num primeiro momento foi: Qual a quantidade de Erva-Mate cultivada e de fardos produzidos em determinada área plantada? O Episódio 1 ilustra os questionamentos levantados pelos alunos na intenção de encontrar uma resposta para a pergunta que haviam formulado.

Episódio 1

Ep: Qual fórmula devo usar?

Prof.: Para que?

Ep: Para calcular a quantidade de fardos de Erva.

Ca: É professora, onde tem exemplo disso?

Prof.: Exemplo do que?

Ca: De como calcular a quantidade de Erva-Mate cultivada e de fardos produzidos.

Prof.: Vocês vão considerar o intervalo de tempo entre as colheitas? 
Ep: Não tem nada igual no caderno? E no livro?

Prof.: Talvez tenha. Mas vocês devem saber o que estão procurando.

Gi: Mas não têm pronto? Que dê a resposta pronta? Uma fórmula matemática?

Atenta aos diálogos dos alunos, a professora identificou uma necessidade que os alunos tinham de dispor de uma "fórmula" para resolver, traços da forma como aprenderam matemática até o momento. Como em atividades de modelagem matemática, na maioria das vezes, não existe uma fórmula pronta, ao contrário, busca-se encontrar um meio de resolver o problema a partir de um processo de matematização da situação, os alunos acabaram identificando uma nova situação que poderiam estudar, dada as intervenções da professora.

No diálogo do Episódio 1 o procedimento de olhar novamente para o tema e a preocupação de encontrar uma fórmula matemática que descrevesse o problema identificado, provocou certa inquietação na busca por uma informação, um método ou uma fórmula matemática capaz de responder prontamente ao problema evidenciado.

Com a orientação da professora e com o olhar voltado para as informações que possuíam, os alunos passaram a organizar melhor a ideia e pensar em outra estruturação para o problema, chegando à seguinte questão: Existe uma fórmula matemática capaz de descrever a produção de Erva-Mate dependendo da área de cultivo em relação à distância do plantio entre uma muda e outra e o tempo de extração? Estruturar a pergunta de modo a atender as inquietações e interesse dos alunos é um procedimento manifesto que levou à formulação de um questionamento que considera curiosidades por eles demonstradas.

A orientação da professora nesse caso foi que eles retomassem as informações e pensassem nos elementos e dados que precisariam dispor para responder ao problema estruturado. O Quadro 2 apresenta os dados que os alunos consideraram mais relevantes para ajudar a responder o problema.

Quadro 2 - Síntese das informações mais relevantes sobre a Erva-Mate

Síntese das informações mais relevantes sobre a Erva-Mate

A cada 4 anos, um pé de erva mate rende em média $2 \mathrm{Kg}$.

A cada 6 anos, um pé de erva mate rende em média $6 \mathrm{Kg}$.

A cada 15 anos, um pé de erva mate pode render, em média, $30 \mathrm{Kg}$.

A distância de plantio é a cada $1,5 \mathrm{~m}$.

Terreno retangular.

Erva-Mate verde rende a metade depois de seca.

Um fardo possui 30 pacotes de $1 \mathrm{Kg}$.

Fonte: Castro (2017).

O procedimento de sintetizar as informações que usariam na resolução do problema evidenciado possibilitou que os alunos viessem a retomar seus conhecimentos e simplificar as informações acerca do tema e da situação em estudo. Foi preciso, a partir de tais informações, identificar conceitos e métodos 
para buscar um resultado apropriado. O Episódio 2 retrata como tal busca foi iniciada.

\author{
Episódio 2 \\ Prof.: Como calculamos a área de um retângulo? \\ Ep: É a base vezes a altura. \\ Prof.: Isso! Base vezes altura. E se ele for um terreno retangular não conheça \\ a medida dos lados, como representar? \\ Al: Usando " $x$ ". \\ Prof.: Muito bem. Um dos lados pode ser " $x$ ". E o outro? \\ Gi: O outro pode ser " $y$ ". \\ Prof.: Ok, x e y. Como nós fazemos para calcular a área do terreno? \\ Al: Base vezes altura. \\ Prof.: Se aqui a base mede x e a altura mede y, como ficará? \\ Ca: Mas vai ficar $x$ vezes $y$ ? \\ Prof.: Sim. Essa é a representação algébrica. \\ Al: E quanto vale o x e o y? \\ Prof.: $O$ x e o y quer dizer que essa forma vai valer para qualquer medida de \\ um terreno retangular. Esses valores podem variar. Para calcular a \\ quantidade de Erva-Mate produzida como nós faremos? Qual era a distância \\ de plantio entre um pé de erva e outro? \\ Ep: Divide por 1,5m.
}

No Episódio 2 os alunos discutem sobre os conceitos e estratégias matemáticas que usariam para construir a fórmula capaz de descrever uma solução para o problema. Para tanto, durante o diálogo mediado pela professora, buscam compreender os cálculos realizados, bem como o processo de resolução do problema passo a passo. Assim, o procedimento dos alunos foi interpretar a resolução matemática realizada, em que primeiro determinavam os lados do terreno $(\mathrm{m})$; depois calcularam a área do terreno $(\mathrm{m} 2)$; em seguida obtiveram a quantidade máxima de pés de Erva-Mate cultivados na área, para finalmente obter a quantidade de Erva-Mate produzida (pronta), bem como a quantidade de fardos. A partir de então, juntamente com a professora, passam a construir uma representação algébrica dos algoritmos utilizados durante o desenvolvimento da atividade. Tal procedimento indica que os alunos conseguiram interpretar e/ou compreender os processos matemáticos envolvidos na busca por solução para o problema e puderam reutilizá-los para traçar novas estratégias de resolução.

Eles usaram, de maneira geral, todos os dados simultaneamente, já que todos relacionados e dependiam uns dos outros. Assim, consideraram hipoteticamente um terreno retangular com medidas $x$ e $y$ e fizeram, separadamente, para intervalos de 4, 6 e 15 anos entre as colheitas.

Na Figura 1 aparece como os alunos trabalharam na situação utilizando vários elementos ao mesmo tempo: um lado do terreno dividido por 1,5 (distância de plantio) multiplicado pelo outro lado do terreno também dividido por 1,5, isso tudo multiplicado pela quantidade de erva verde extraída (de acordo com o intervalo de tempo) e dividido por 2 (pois diminui a massa pela metade quando seca). Assim, chegaram às fórmulas explícitas também na Figura 1. 
Figura 1 - Fórmulas obtidas pelos alunos

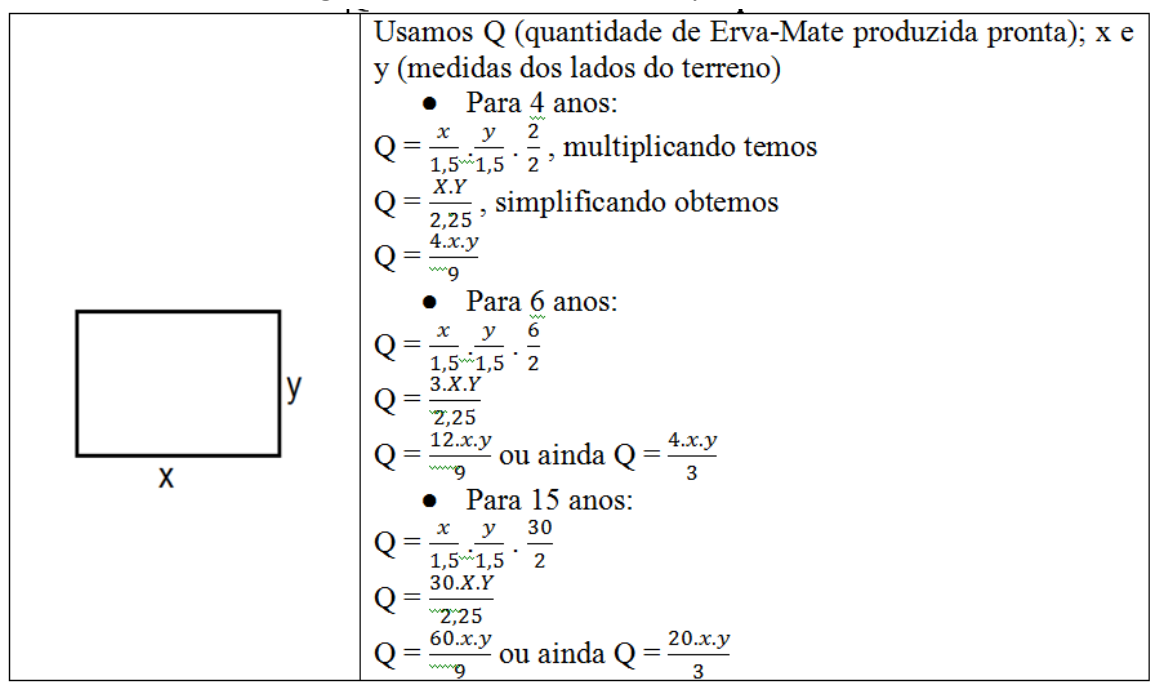

Fonte: Castro (2017).

Para chegar a uma fórmula final para cada intervalo de tempo entre as colheitas, os alunos precisaram relembrar conceitos matemáticos tais como: multiplicação e divisão de frações, transformação de números decimais e frações equivalentes. Nesse momento, foram determinantes as contribuições da professora, que sempre dava orientações e explicações ao grupo. A compreensão ou retomada desses conceitos colaborou para a construção das fórmulas matemáticas que foram consideradas modelos matemáticos para a situação em estudo. Ou seja, os procedimentos de mobilizar conhecimentos matemáticos prévios ou aprender novos e construir um modelo matemático, levaram à manipulação de algoritmos matemáticos, à medida que os alunos recorriam constantemente às informações e técnicas matemáticas que dispunham e/ou aprendiam e resolviam o problema evidenciado.

Para verificar a validade das fórmulas deduzidas, os alunos calcularam para os mesmos valores que eles haviam utilizado antes e calculado passo a passo. Porém, ao calcular o primeiro valor, cuja medida dos lados do terreno quadrado era $40 \mathrm{~m}$, os alunos obtiveram uma resposta não aceita por eles (Figura 2). 0 resultado obtido a partir da fórmula não condiz com o resultado inferido quando realizaram seus cálculos passo a passo, cujo valor encontrado foi de $676 \mathrm{~kg}$. Assim, a professora refez com eles da forma "por extenso", como haviam feito anteriormente, favorecendo com que eles confirmassem que a resposta de $676 \mathrm{~kg}$ era correta.

Figura 2 - Teste da fórmula obtida

Terreno de $40 \mathrm{~m} \times 40 \mathrm{~m}$

$$
\begin{gathered}
\mathrm{Q}=\frac{4 . x \cdot y}{m 9} \\
\mathrm{Q}=\frac{4.40 .40}{9} \\
\mathrm{Q}=\frac{6400}{9} \\
\mathrm{Q}=711,1111 \ldots .
\end{gathered}
$$

Fonte: Castro (2017). 
O procedimento de olhar para a resposta obtida a partir do emprego da fórmula e compará-la ao resultado anteriormente aceito e confirmado leva os alunos a verificação da resposta como não válida para aquela circunstância e sinaliza a necessidade de rever a fórmula e os conceitos utilizados até o momento.

Como as únicas variáveis utilizadas na fórmula diziam respeito apenas às medidas dos lados do terreno, concordaram que havia um erro. O Episódio 3 mostra que, o grupo de alunos, a partir de questionamentos da professora, passa a repensar seus cálculos e os valores envolvidos.

\section{Episódio 3}

Ep: São 26 pés inteiros.

Prof.: Para plantar esses 26 pés, são utilizados quantos metros do terreno? Gi: Para plantar esses 26 pés, usaremos..., espera...

Ep: Usaremos a operação 26 vezes 1,5.

Ca: Como é?26?

Ep: 26 vezes 1,5 igual a 39m. Assim podemos usar as fórmulas para calcular.

Nesse recorte do diálogo dos alunos, o procedimento deles foi retomar valores e operações e obter novos resultados parciais ao problema, procedimento que favoreceu a resolução matemática a partir da definição de outros valores a serem aplicados nas fórmulas. Ainda acerca desses valores, a discussão no grupo continua (Episódio 4).

Prof.: Isso. Porque "vai sobrar um pedaço" do terreno que você não vai usar.
}

O procedimento dos alunos, ao passo que compreendem a situação gradualmente, é reconhecer as características matemáticas presentes, associadas às estratégias matemáticas envolvidas. Esse procedimento possibilita aos alunos entender, em linguagem matemática, o significado e conceito de valores envolvidos e utilizados na situação em estudo.

O Episódio 5 retrata o diálogo dos alunos no momento em que realizaram operações matemática para resolver uma equação.

\section{Episódio 5}

Prof.: 4 vezes 39 vezes 39 dividido por 9. Isso é uma fração. Quanto que dá 4 vezes 39 vezes 39 ?

Ep: Dividido por 9?

Prof.: Primeiro multiplica.

Ep: Dá 6084. Dividido por 9. [sic]

Prof.: 6084 dividido por 9.

Gi: Dá 676. [sic]Prof.: Então $Q=676$. Olhe no resultado anterior para verificar.

[...] Depois faz para a fórmula de 6 anos. 
O procedimento de resolver os cálculos matemáticos, elencados no diálogo, sinaliza que os alunos utilizaram métodos e puseram em uso seus conhecimentos matemáticos para representar e resolver o problema evocado.

Ao realizar nova comparação com os cálculos previamente elaborados, perceberam que os resultados eram iguais. Como o valor expresso antes já havia sido verificado e aceito como válido e, o valor obtido por meio do uso da fórmula era o mesmo, a resposta foi assumida como correta. O procedimento dos alunos, de admitir o resultado como correto a partir de uma comparação, indica que eles analisaram a resposta obtida e a consideraram válida para o problema identificado.

Para certificar-se da validade das outras fórmulas, utilizando a mesma ideia compreendida até então, os alunos realizaram cálculos para as situações, conforme Figura 3. Assim, argumentaram que elas apresentavam resultados satisfatórios para quaisquer das medidas consideradas.

Figura 3 - Verificação da fórmula assumida como modelo matemático da situação

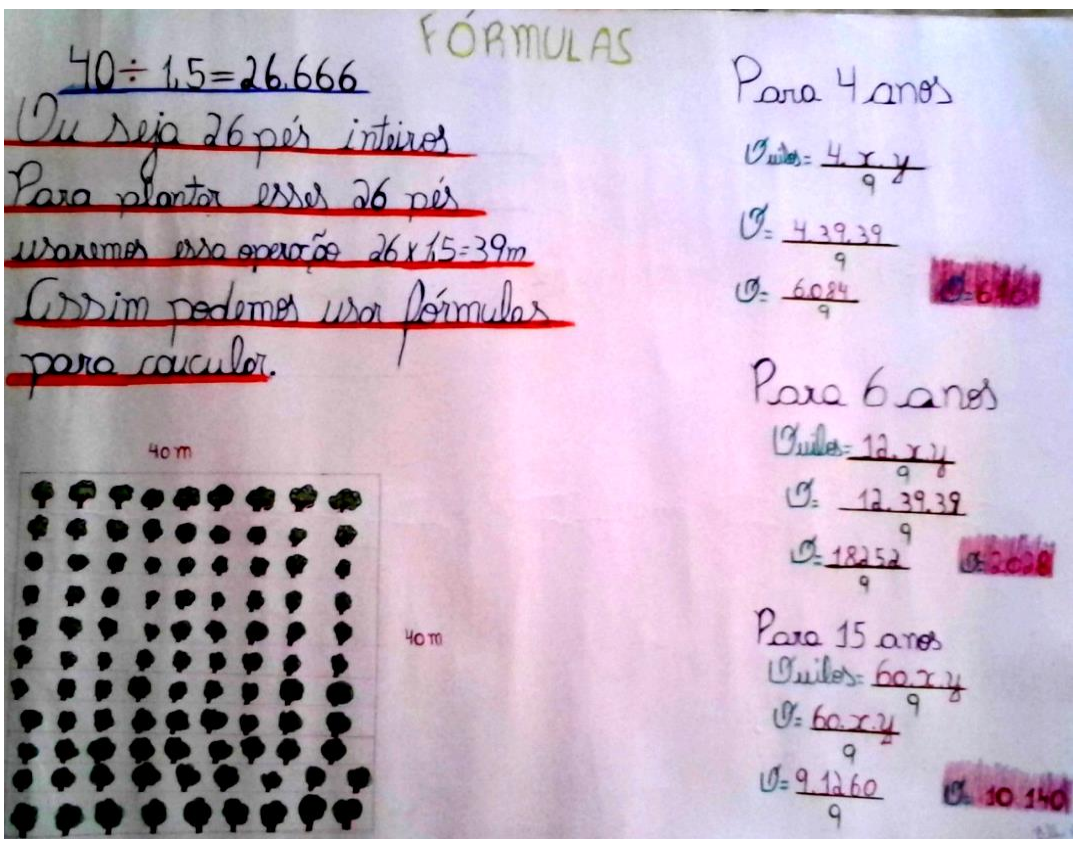

Fonte: Castro (2017).

Ao testar esses valores, de certa forma, reforça-se a certeza dos alunos quanto à validade das fórmulas, deixando-os confiantes para o procedimento de apresentar os resultados aos colegas da turma e à professora por meio da exposição dos resultados e explicação oral. Tal procedimento possibilitou aos alunos, embasados no processo de construção da resposta e verificação dos encaminhamentos assumidos, comunicar a solução por eles encontrada e que, naquele momento, foi aceita satisfatoriamente como resposta para a problemática inicial.

\section{Atividade 2}

O grupo que desenvolveu a atividade com o tema "Planetas do Sistema Solar" 
temática definida. A partir dessa pesquisa, os alunos reunidos em grupo buscam definir uma "pergunta" para investigação, conforme ilustra o Episódio 6.

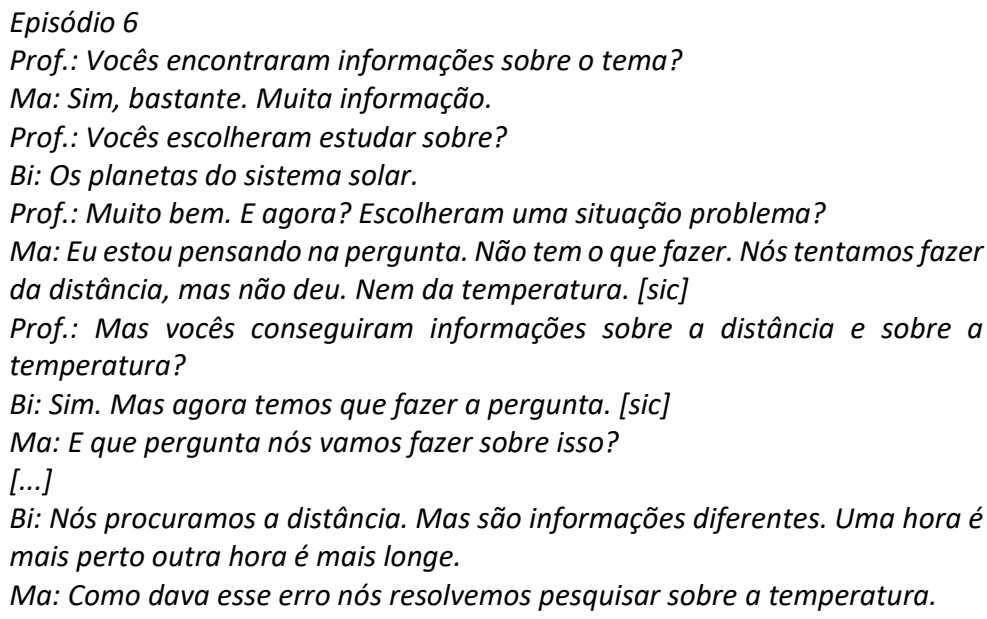

O Episódio 6 retrata a preocupação dos alunos em identificar e/ou elaborar um problema que eles se referem como "pergunta". Diante de tal inquietação eles tentam elaborar uma pergunta atentos a algumas informações sobre o tema, no entanto, comentam que haviam divergências entre elas, em certos aspectos, quando comparavam diferentes fontes de pesquisa. A pesquisa sobre a temática e a busca por definir um problema, entendido pelos alunos como uma pergunta, a partir de informações sobre o tema provoca uma discussão que leva ao reconhecimento de uma possível questão para investigação da temática escolhida para estudo.

Ainda sem ter identificado uma pergunta, o diálogo entre os alunos segue em torno de aspectos da situação e, ao encontrar informações divergentes sobre o tema, a dificuldade em identificar um problema persiste. Tal impasse pode ser percebido no Episódio 7.

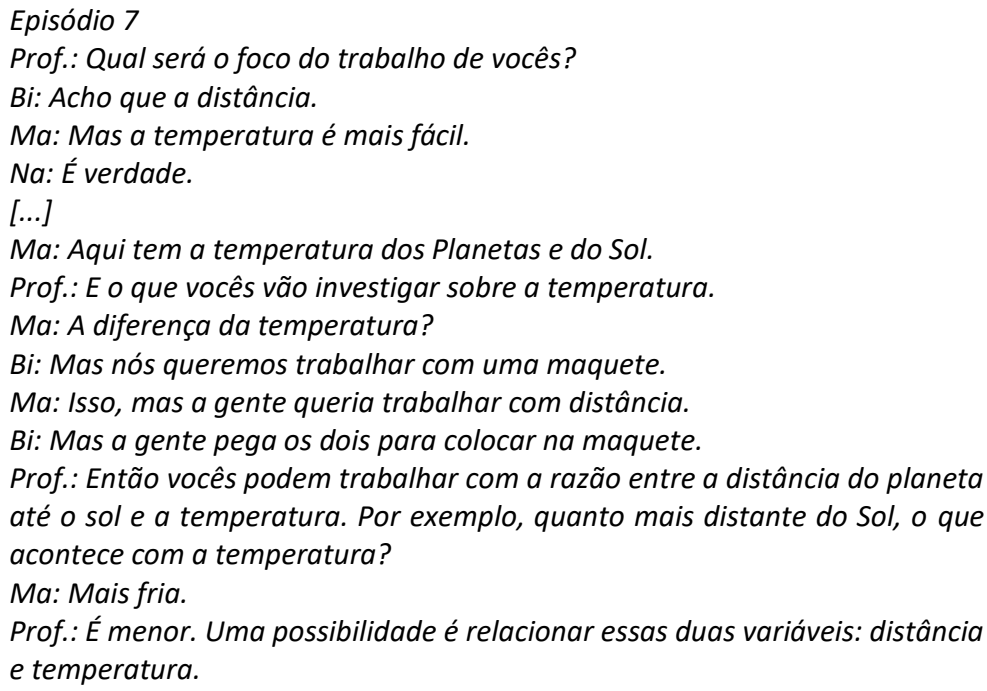

Esse recorte ilustra que o grupo ainda não tem definido um problema de investigação, entretanto, sinaliza uma delimitação frente ao tema em estudo, reduzindo suas opções à distância e à temperatura. Diante dessas duas opções, o aluno Ma sugere trabalhar com a temperatura alegando que seria mais "fácil". Sem 
chegar a um acordo, o aluno Bi fala para "pegar os dois [distância e temperatura] para colocar na maquete". O procedimento de restringir a atividade de investigação e assumir temperatura e distância dos planetas como foco do estudo possibilitou a utilização das informações para simplificar o processo de busca. Assim, começam a encaminhar seus estudos e formular o problema a partir do direcionamento assumido.

O Episódio 8 sinaliza como os alunos formalizam a "pergunta" de investigação já pensando em possibilidades e caminhos para respondê-la.

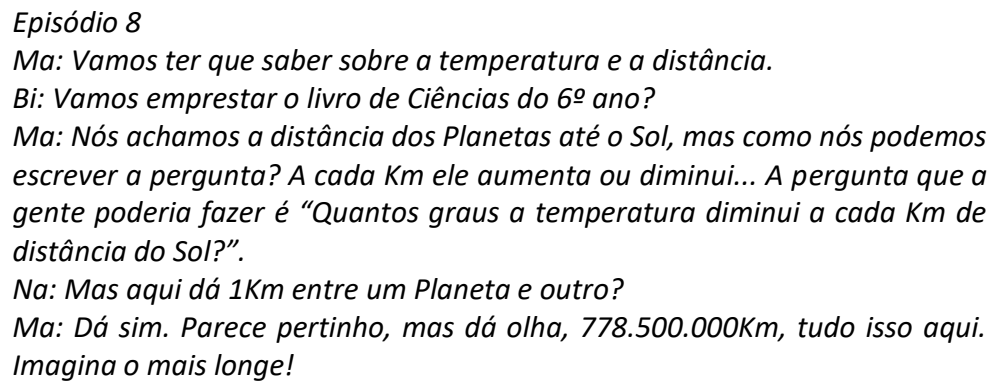

Neste episódio os alunos assumem, de fato, sua opção pelo estudo da distância e da temperatura dos Planetas em relação ao Sol e passam a olhar para a situação com enfoque para suas características matemáticas. Quando o aluno questiona "dá $1 \mathrm{~km}$ ?" e o outro afirma "parece pertinho, mas dá olha, $778.500 .000 \mathrm{Km}$ ", nos remete a considerar que o procedimento de deliberar sobre o problema em seus aspectos matemáticos permitiu essa transição da linguagem natural para a linguagem matemática.

A partir da interpretação matemática da situação os alunos passam para um momento de busca por resolver matematicamente o problema, conforme retratado no Episódio 9.

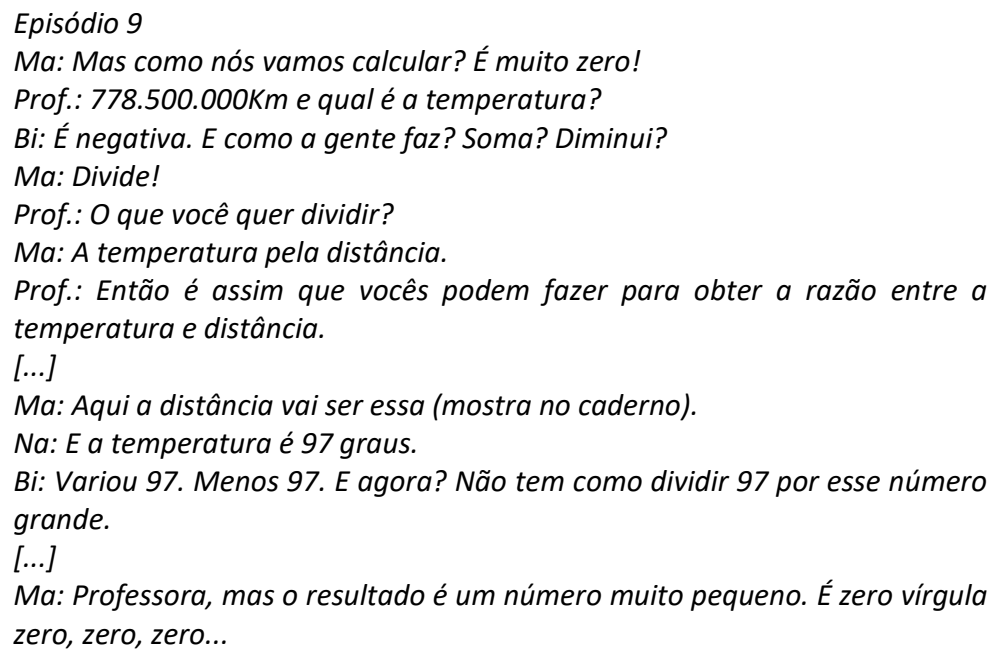

Os termos utilizados pelos alunos, do tipo: "como nós vamos calcular?", "divide a temperatura pela distância" e "é um número muito pequeno. É zero vírgula zero, zero..." indica que o procedimento do aluno foi de utilizar estratégias matemáticas. Esse procedimento pode ter levado os alunos, a partir de métodos matemáticos e com o auxílio da calculadora, a inferir um resultado para o problema. 
Entretanto, no Episódio 10, notamos que houve um bloqueio dos alunos durante seu envolvimento com a resolução do problema identificado. Tal bloqueio os provoca a repensar sobre o encaminhamento assumido e a intenção para com o tema.

\author{
Episódio 10 \\ Bi: Não sei mais se eu quero fazer sobre isso. \\ Na: É, a gente só queria ver os "planetinhas" (risos). \\ Prof:: O que vocês pensaram quando vocês escolheram esse tema? \\ Bi: Na maquete. Mas nós não sabíamos que teria tanta informação assim! \\ Ma: A gente queria trabalhar com a distância e a temperatura. \\ Prof:: Mas o que vocês estão fazendo?! \\ Bi: É, mas está bem difícil. \\ Prof.: E agora, como vocês pensam em fazer? Vocês pensam em continuar \\ com esse problema ou elaborar outro. \\ Bi: Mas qual? \\ Na: Nós queríamos falar de tudo ao mesmo tempo. \\ Ma: E a gente não pensou que teria tanta coisa para estudar! \\ Prof.: Se vocês pensaram na maquete, o que vocês poderiam colocar na \\ maquete? \\ Bi: A gente vai ter que trabalhar a distância.
}

Apesar de ter iniciado a resolução do problema, os alunos ainda não se sentiam estimulados a seguir os encaminhamentos assumidos em momento anterior, nem os sugeridos pela professora. Quando a professora questiona "O que vocês pensaram quando vocês escolheram esse tema?" tem como intuito fazer os alunos se expressarem para que, junto com eles, pudessem pensar em outras possibilidades de resolução do problema ou mesmo um novo direcionamento para a atividade de modelagem. Isso reforça a ideia de que atividades de modelagem matemática têm a característica de serem flexíveis e, caso o aluno não se sinta motivado a estudar sobre o problema proposto, ele pode recomeçar.

Mesmo o tema tendo sido escolhido pelos alunos, nesse momento eles não se sentiam motivados a prosseguir o estudo. Embora interessados em estudar sobre características de cada Planeta, individualmente, e construir uma maquete capaz de representar o Sistema Solar eles precisaram retomar aspectos da situação. 0 procedimento dos alunos, nesta ocasião, foi repensar, reconsiderar as informações e definir novos encaminhamentos para o problema e possibilitou aos alunos, olhando para o material que tinham disponível, propor um outro problema a ser estudado a partir do objetivo inicial que era a construção de uma maquete.

Com o novo foco definido, os alunos passam à busca por uma solução tal problema, conforme retratado no Episódio 11.

Episódio 11

Bi: Dá para fazer a maquete na diagonal do retângulo.

[...]

Ma: Se nós fôssemos representar em escala, nós precisaríamos de $8 \mathrm{~m}$ para fazer a distância do planeta mais longe do Sol. Olha, para fazer de $1 \mathrm{~cm}$ representando 5 milhões de $K m$, 4497 divide por 5 dá 899,4cm.

Prof. Mais de $8 \mathrm{~m}$, na verdade quase 9. Tudo isso? Então vamos reduzir a escala.

Bi: Não dá para fazer "na louca"? [sic]

Ma: Vamos fazer os que estão mais perto representar com uma distância menor e os que estão mais afastados um do outro com uma distância maior. 
Na: Pode ser eu acho.

Prof.: Vocês vão colocar a temperatura, a distância até o Sol e o raio de cada planeta?

Ma: Isso. Vamos por em uma plaquinha.

No diálogo dos alunos percebemos que eles, com a orientação da professora, passam a discutir o método de construção da maquete e, como eles próprios enfatizam durante suas discussões acerca do tema, a utilização das informações relativas à distância de cada planeta até o Sol. Nas afirmações "4497 divide por 5 dá 899,4cm", "na diagonal do retângulo" ou "mais perto com uma distância menor" percebemos indícios de que os alunos manipulam dados matemáticos úteis na elaboração do material da maquete. Esse procedimento de utilizar informações matemáticas levou a mobilizar conhecimentos sobre conceitos matemáticos.

Com os resultados em mãos os alunos organizam os dados em uma tabela (Tabela 1), apresentando a distância real de cada planeta até o Sol e essa distância em escala de $1 \mathrm{~cm} / 50 \mathrm{mi} . \mathrm{Km}$.

Tabela 1 - Escala da distância entre os Planetas do Sistema Solar

\begin{tabular}{ccccccccc} 
& $\begin{array}{c}\text { Merc } \\
\text { úrio }\end{array}$ & Vênus & Terra & Marte & $\begin{array}{c}\text { Júpit } \\
\text { er }\end{array}$ & $\begin{array}{c}\text { Satur } \\
\text { no }\end{array}$ & Netuno & Urano \\
$\begin{array}{c}\text { Tamanho } \\
\text { real } \\
(\mathrm{mi} / \mathrm{km}) \\
\begin{array}{c}\text { Escala } \\
(1 \mathrm{~cm} / 50\end{array}\end{array}$ & 57,9 & 108 & 149 & 228 & 778 & 1427 & 2870 & 4497 \\
$\mathrm{mi} . \mathrm{Km})$ & 1,158 & 2,16 & 2,98 & 4,56 & 15,56 & 28,54 & 57,4 & 98,94 \\
\hline
\end{tabular}

Fonte: Castro (2017).

O procedimento de construir essa tabela possibilitou aos alunos simplificar seu estudo ao passo que organizaram suas ideias nesse formato. Tal tabela também indica que os alunos assimilaram o processo de representação em escala e seus respectivos cálculos e, pela aplicação de técnicas matemáticas, foram capazes de encontrar os resultados.

A tabela construída pelos alunos contém os resultados das escalas, os quais foram interpretados a fim de marcar, na maquete, a posição de cada planeta em relação ao Sol. O Episódio 12 ilustra como os alunos interpretam os dados da tabela e como tratam as informações, visando à construção da maquete.

\section{Episódio 12}

Ma: Aqui nós vamos ter que medir do Sol, $1,15 \mathrm{~cm}$ e colocar o planeta Mercúrio. Aí nós colocamos as informações sobre ele perto do palito.

Bi: Vamos fazer assim na diagonal?

Na: Podemos desenhar com tinta e colar com fita larga.

Ma: Vamos marcar a distância, depois nós desenhamos e colamos. E a Terra, quantos $\mathrm{cm}$ do Sol?

Bi: Mas o Sol vai ficar bem nesse cantinho?

Ma: Sim. Daí nós medimos do Sol até o planeta usando a tabela com a escala. [...]

Bi: É professora! O que é perto é muito perto e o que é longe é longe demais 
A forma de analisar e discutir sobre a tabela viabiliza a interpretação do significado dos valores em escala obtidos em seus cálculos, passando a empregálos ao manusear os materiais que constituem a maquete do Sistema Solar. A percepção do aluno que "o que é perto é muito perto e o que é longe é longe demais!", procedeu do fato de que os alunos, ao buscar representar a distância de Mercúrio até o Sol, notaram ser pequeno o valor de $1,15 \mathrm{~cm}$ para representar na maquete. Esse procedimento de analisar as soluções e interpretar seu significado indica que o aluno realizou a verificação e aplicação das respostas matemáticas obtidas durante sua investigação.

Para representar os planetas os alunos trouxeram esferas de isopor de diferentes tamanhos. Com isso, precisaram conhecer o tamanho do diâmetro da circunferência de cada planeta para organizar a ordem das esferas na disposição no Sistema Solar. O procedimento de efetuar cálculos como a medida do raio, do diâmetro e do comprimento da circunferência dos planetas possibilitou reconhecer conceitos matemáticos envolvidos na situação em estudo e realizar considerações acerca dos métodos empregados para a resolução dos cálculos.

Tabela 2 - Características dos Planetas

\begin{tabular}{|c|c|c|c|c|c|c|c|c|}
\hline & Mercúrio & $\begin{array}{c}\text { Vênu } \\
\text { s }\end{array}$ & Terra & Marte & Júpiter & $\begin{array}{c}\text { Saturn } \\
\text { o }\end{array}$ & Urano & Netuno \\
\hline $\begin{array}{l}\text { Diâm } \\
\text { etro } \\
(\mathrm{km})\end{array}$ & 4878 & 12000 & 12756 & 6787 & 142800 & 120600 & 518000 & 49100 \\
\hline $\begin{array}{l}\text { Raio } \\
(\mathrm{km})\end{array}$ & 2439 & 6000 & 6378 & 3398,5 & 71400 & 60300 & 259000 & 24550 \\
\hline $\begin{array}{c}\text { Circu } \\
\text { nferê } \\
\text { ncia } \\
\text { equat } \\
\text { orial } \\
\text { (km) }\end{array}$ & 15316,92 & 37680 & 40053,8 & 21311,18 & 448392 & 37684 & 1626520 & 154174 \\
\hline
\end{tabular}

Fonte: Castro (2017).

Ainda, ao calcular a circunferência equatorial de cada planeta, usando a fórmula do comprimento de circunferência, os alunos chegaram a duas conclusões importantes: quanto maior o raio, maior será o comprimento da circunferência, portanto, os planetas poderiam ser organizados conhecendo-se o raio, o mesmo vale para o diâmetro e; $C=2$.r.r é o mesmo que $C=\pi$.d, conhecendo o diâmetro não precisariam obter o tamanho do raio para calcular o comprimento da circunferência. $O$ procedimento do aluno de reconhecer tais características matemáticas a partir do cálculo do comprimento da circunferência, interpretando o significado dos seus cálculos e percebendo novas possibilidades possibilitou realizar tais conclusões.

Associada ao processo de interpretação da resolução da situação problema houve a aceitação dos resultados obtidos e a comunicação aos demais alunos da sala e para a professora e, a partir da maquete, os alunos conseguiram ilustrar suas 
explicações sobre a investigação realizada. O procedimento de o aluno expor sua investigação, realizar argumentações sobre os encaminhamentos assumidos para se chegar aos resultados explanados, favoreceu, além da apresentação do trabalho desenvolvido, o convencimento de que os resultados eram consistentes e os conceitos matemáticos eram adequados para aquele estudo.

Nessa atividade, notamos que houve, a princípio, uma preocupação com a "pergunta" orientadora da atividade de modelagem matemática. Talvez isso tenha se dado em virtude de ser bastante comum o problema gerador de uma atividade de modelagem vir em forma de pergunta. Contudo, o que sustentou o desenvolvimento da atividade dos Planetas do Sistema Solar foi o desejo dos alunos em construir um material capaz de representar as características matemáticas mais notáveis, do ponto de vista deles, dos planetas do Sistema Solar.

\title{
Atividade 3
}

O grupo formado por 3 alunos, aqui denominados El, Al e Lu, optaram pela escolha do tema Milho porque, segundo eles, não tinham um conhecimento tão amplo sobre o tema, porém tinham curiosidade em estudá-lo e encontraram na Modelagem Matemática uma oportunidade de desenvolver tal estudo.

Essa escolha levou-os a buscar informações acerca do referido tema, conforme descrito no Episódio 13.

\author{
Episódio 13 \\ El: Estou procurando uma tabela. \\ Prof.: Mas tabela do que você está procurando? O que você quer saber sobre \\ o milho? Tabela de plantação, de produção, tabela de venda, de preço? \\ Especifique sua busca que fica mais fácil. \\ El: Tem tanta tabela que eu nem sei o que faço. \\ Prof.: No mundo, nos EUA, na China, no Brasil, na Rússia e na Argentina. E o \\ que você vai fazer com isso? \\ El: Não sei. Aqui tem, mas fala de anéis de silos..
}

Ainda sem ter definido o problema, os alunos estavam preocupados em encontrar uma "tabela" que continha informações gerais sobre Milho, ou seja, buscavam por conhecer sobre o tema sem uma delimitação pré-estabelecida.

Ao acessar materiais com informações sobre milho, sendo estes: anotações no caderno, realizadas a partir da pesquisa na internet, panfletos, folders, revistas e embalagens de produtos a base de milho, os alunos realizaram uma seleção dessas informações. Visando compreender sobre o tema escolhido, eles perceberam a necessidade de conhecer o significado de termos e características referentes à produção, ao armazenamento e ao comércio do milho, assim como o termo anéis de silos.

O procedimento de busca por informações e de conhecer sobre o tema por meio de pesquisa contribuiu para que os alunos realizassem sua busca e, com orientação da professora, selecionassem as informações que lhes eram significativas neste momento.

Decorrente do processo de compreensão, ainda ao se inteirar do assunto, surgiram dúvidas complementares e os alunos começaram a elencar outras perguntas (matemáticas ou não) sobre o Milho e respondê-las. 
Ao passo que buscavam responder as questões levantadas, os alunos passam a elaborar novos questionamentos e estruturar suas ideias de investigação. 0 procedimento de organizar e amadurecer suas ideias em relação aos problemas a serem estudados sobre o Milho, selecionando os dados mais relevantes, auxiliou os alunos a formular um problema que originou o desenvolvimento dessa atividade de modelagem.

A partir do diálogo entre o grupo e a professora (Episódio 14), com destaque para a forte influência e persuasão de um dos membros mais ativos (EI) do grupo, o seguinte problema foi formulado: Dependendo do tamanho dos silos, qual sua capacidade de armazenamento de milho?
Episódio 14
El: E ainda temos essas informações. Como que nós podemos elaborar uma pergunta?
Prof.: Vamos observar quais são as informações presentes nessas tabelas que vocês têm.
El: Traz alguma coisa sobre a capacidade aqui olha... aqui é 28, aqui é 13 toneladas.
Prof.: Mas fala que é entre 28.000 e 13.392,51 toneladas. Quer dizer que depende do tamanho. Essas informações vocês podem usar.
EI: E o que quer dizer essas informações aqui?
Prof.: Ton $/ \mathrm{m}^{3}$ ? Um metro cúbico refere-se a volume. Como se fosse uma caixa, de um metro de comprimento, por um de altura e um metro de largura. Quer dizer que em $1 \mathrm{~m}^{3}$ caberá 0,75 ton. Vocês podem descobrir quantos $\mathrm{Kg}$ isso representa.
El: Aí o volume em metros cúbicos dá para sabermos quantas toneladas vai? Prof.: Se sabemos quantas toneladas cabem em $1 \mathrm{~m}^{3}$, conseguimos calcular quando soubermos o volume do silo.
[...]
El: Qual o tamanho dos silos e qual a capacidade de armazenagem? Tem de vários tamanhos, gente! E vários tipos de silos. Precisaremos definir alguns.

O problema matemático a ser investigado, neste caso, foi definido a partir do conhecimento a respeito de alguns aspectos matemáticos envolvidos. Nesse diálogo, os alunos estudaram informações relativas ao tema, elencando algumas possibilidades e realçando características matemáticas que Ihes chamava a atenção, isto é, a partir de informações matemáticas, questionamentos e um breve esclarecimento feito pela professora, eles tiveram um insight ao afirmar que "aí o volume em metros cúbicos dá para sabermos quantas toneladas vai?" que os levou a estruturar a situação problema a ser investigada. O procedimento do aluno, atendo-se aos dados matemáticos, de estruturar e formular o problema indica que os alunos foram capazes de simplificar sua busca.

No momento em que o aluno expõe o problema formulado como sendo "Qual o tamanho dos silos e qual a capacidade de armazenagem?", e logo em seguida exclama "Tem de vários tamanhos, gente! E vários tipos de silos" leva-o a preocupar-se em delimitar seus estudos. É a afirmação por ele proferida "Vamos ter que definir alguns", referindo-se ao tamanho dos silos, que delimita o estudo das condições matemáticas que constituem o formato de um silo.

O estudo de uma imagem de um silo circular (Figura 4) e o reconhecimento de alguns de seus elementos (teto, coluna, anéis, saia, parede cilíndrica, altura e raio), impõe a necessidade dos alunos buscarem, em um livro didático, aspectos sobre o formato, nome e elementos do sólido que melhor representa o silo em questão e como seria possível calcular o volume desse sólido. Os alunos manifestam, 
portanto, o procedimento de pesquisa e reconhecimento de informações matemáticas bem como o de transição de linguagens, isto é, a interpretação do problema em linguagem matemática que lhes serviria de subsídio para resolver o problema.

Figura 4 - Silo circular

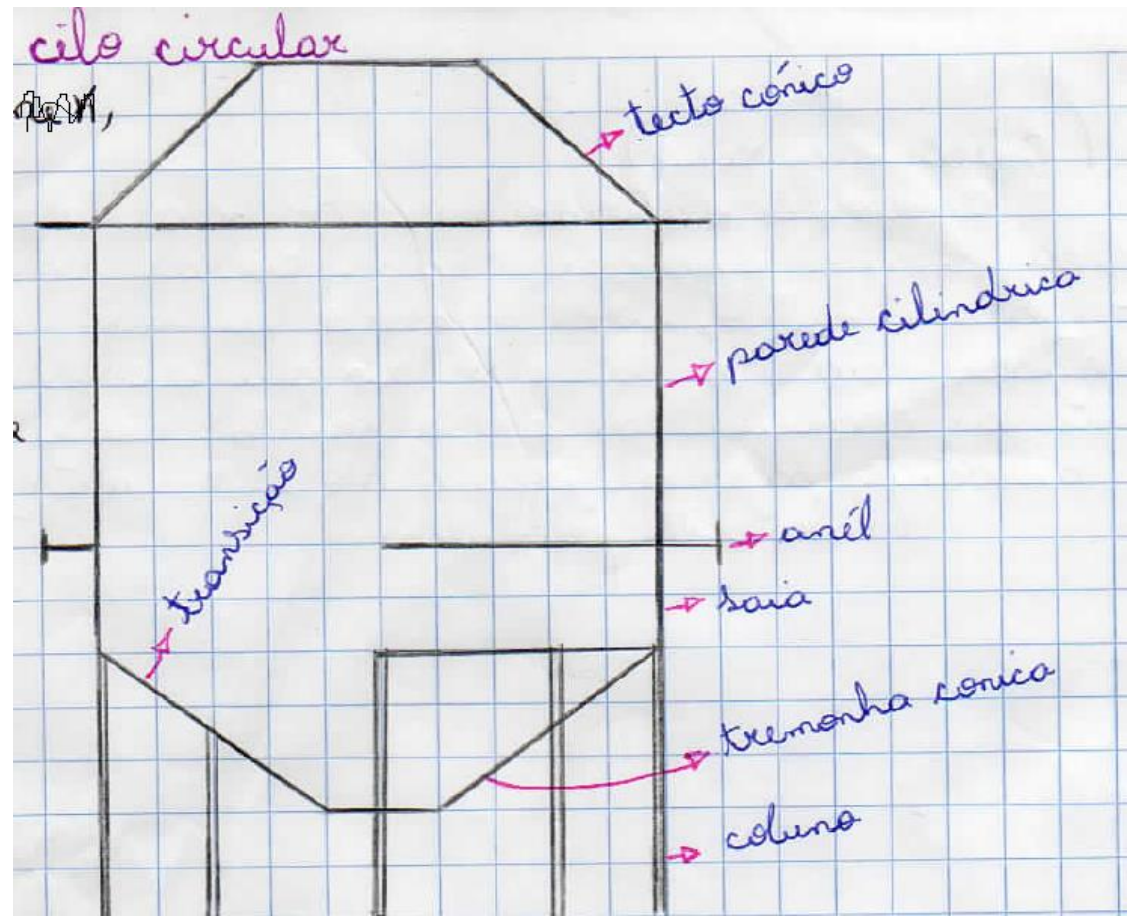

Fonte: Representação realizadas pelos alunos.

O Episódio 15 apresenta a conversa dos alunos em torno do formato do silo e da seleção de variáveis que eles fazem, bem como da justificativa dada pela escolha realizada para resolver o problema.

\section{Episódio 15}

El: Vamos fazer uma tabela.

Lu: Como?

El: Qual que nós vamos fazer? Vamos fazer o primeiro que é mais fácil! O número de anéis a gente tira. A de 60 graus é mais fácil! Daí aqui põe toneladas, 60ton...

Lu: Por que tanto número junto?

El: E a altura do corpo?

$[\ldots]$

Prof.: Os silos que vocês conhecem são nesse formato?

Al: Não. Eles não têm esse "negócio" aqui embaixo.

El: Ele é mais parecido com isso (mostra o cilindro no livro). Esse que nós desenhamos teria que juntar essa figura (cilindro) e essa outra (tronco de cone).

Prof.: Como vocês farão?

El: Podemos fazer desse, que é cilindro? Porque vai ser mais fácil e é como os silos que nós conhecemos. Desse outro tipo eu nunca vi.

A partir da pesquisa nos livros didáticos, o procedimento dos alunos, com a orientação da professora, foi definir o estudo sobre o cilindro, por ser o sólido geométrico que, para eles, era a melhor representação de um silo de armazenamento e também porque julgavam ser "mais fácil" visto que não 
precisariam dispor de muitos algoritmos. Esse procedimento de olhar e buscar entender as informações disponíveis, bem como selecionar aquelas que estavam mais próximas da sua realidade e mais simples de resolver, indica que os alunos relacionaram ideias e atribuíram significado para o problema em foco.

Após a compreensão que incidiu na escolha do silo cilíndrico para estudo, os alunos passam a aprofundar seu diálogo sobre como resolver o problema que consistia em calcular o volume do sólido em questão, conforme mostra o Episódio 16.

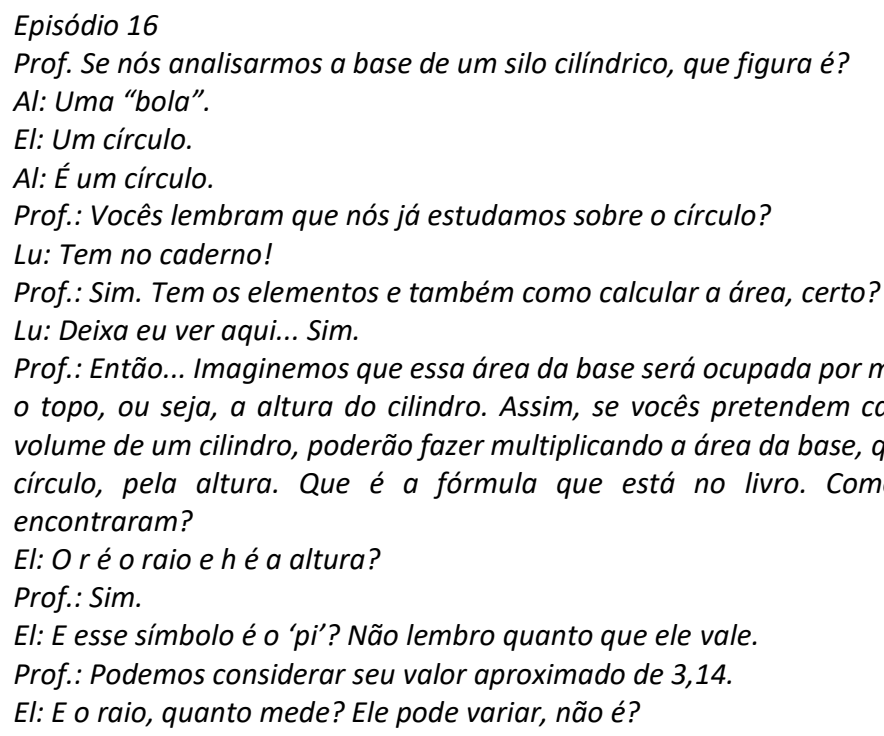

Os alunos reconhecem o raio e a altura como principais elementos do cilindro e identificam que a sua base é um círculo, figura sobre a qual eles apresentavam conhecimento prévio, ou seja, conheciam seus elementos e sabiam calcular a área da base. Bastaram algumas explicações complementares da professora para eles entenderem que a altura também deveria ser considerada para obter o volume do silo. Com tais conhecimentos adquiridos, para calcular o volume do silo em formato cilíndrico, os alunos optaram por variar o tamanho do raio. Entender técnicas e conceitos matemáticos necessários para resolver um problema e definir a grandeza matemática que sofreria variação, se configuram como procedimentos que colaboram para o entendimento, em linguagem matemática, dos dados envolvidos no problema.

A partir da interpretação dos conceitos matemáticos envolvidos os alunos utilizaram a fórmula $V=\pi . r^{2} . h$, em que $\pi . r^{2}$ é a área da base e $h$ é a altura do cilindro, para calcular o volume total do silo. No entanto, consideraram o raio variável e fixaram a altura em $10 \mathrm{~m}$. Tal encaminhamento aponta que o procedimento dos alunos foi resolver matematicamente a situação e encontrar resultados matemáticos para o problema (Figura 5). 
Figura 5 - Volume de um silo de armazenamento

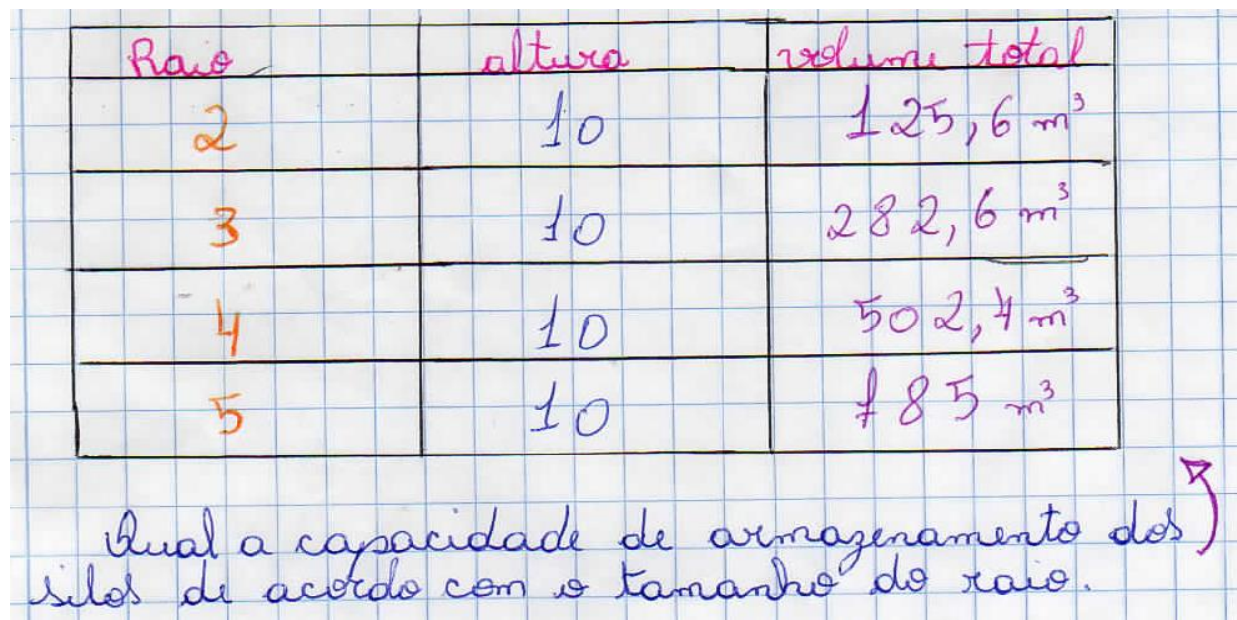

Fonte: Registro dos alunos.

A organização da Figura 5 associada às orientações da professora favorece a análise dos resultados obtidos para o volume total do silo de altura fixa $(10 \mathrm{~m})$ e raio variável (2,3, 4 e 5m), conforme ilustra o Episódio 17.

\author{
Episódio 17 \\ Prof.: Qual era a capacidade de armazenamento de milho nos silos cilíndricos \\ de acordo com o tamanho do raio, esse era o trabalho de vocês, certo? \\ Lu: Sim. \\ Prof.: E vocês conseguiram? \\ Lu: Deu isso daqui, os resultados são esses da tabela. \\ El: Um silo com raio $2 \mathrm{~m}$ e altura $10 \mathrm{~m}$ tem volume $125,6 \mathrm{~m}^{3}$. O de raio 3 deu \\ $282,6 m^{3}$. \\ Prof.: Sim, mas isso é só o volume do silo, correto? \\ El: É verdade. Mas e a capacidade não é a mesma coisa? \\ Prof.: Será? O volume do silo é medido em que? \\ El: Metros cúbicos. \\ Prof.: Cada $\mathrm{m}^{3}$ armazena quanto de milho? Vocês lembram? \\ El: Está anotado aqui... 0,75 ton $/ \mathrm{m}^{3}$. Ah, entendi. \\ Al: Eu não entendi! \\ El: Mas dai $1 \mathrm{~m}^{3}$ cabe isso? \\ Prof.: Sim. Conseguiu entender agora a diferença entre o volume e a \\ capacidade de armazenamento? \\ El: Sim. O volume é do silo seco e a armazenagem é a quantidade de milho \\ que cabe nele. Só multiplicar o volume por 0,75.
}

Nesse diálogo fica evidente que os alunos sabiam explicar o que os resultados descrevem (volume do silo), porém quando a professora intervém, chama-os a analisar sua pergunta e depois as respostas, buscando favorecer a sua percepção de que o volume do silo não satisfaz por completo o problema por eles estruturado, porque buscavam a capacidade de armazenamento de milho. Esse procedimento de olhar para o resultado obtido, interpretar seu significado e associá-lo ao problema inicial julgando-o satisfatório ou não para o contexto em estudo, viabilizou a síntese de resultados, comparação e articulação de respostas com a situação inicial.

Ainda no Episódio 17 notamos que, ao reconhecer que os resultados obtidos 
os volumes dos silos (os quais eles já haviam calculado) por $0,75 \mathrm{ton} / \mathrm{m}^{3}$. Isso nos mostra que o procedimento do aluno foi de complementar a solução por meio da realização de um novo cálculo.

Para apresentar os resultados a professora sugere aos alunos representar os silos em tamanho reduzido, ou seja, sugerem que utilizem uma escala para reproduzir um silo cilíndrico nos tamanhos que haviam definido (Episódio 18).

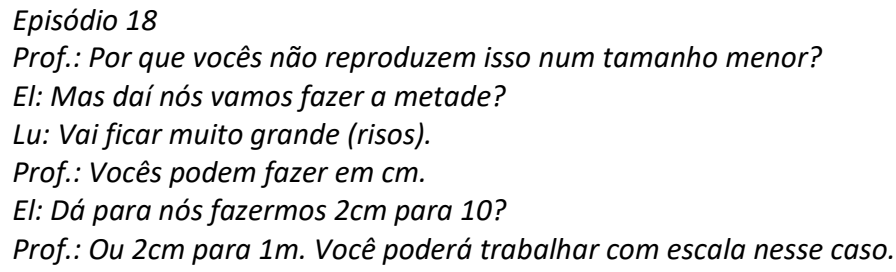

O aluno El ao falar "Dá para nós fazermos $2 \mathrm{~cm}$ para 10 " deixa claro que existe uma noção de reduzir o tamanho real para um tamanho menor, embora a ideia ainda não esteja bem formada (se é $2 \mathrm{~cm}$ para $10 \mathrm{~cm}$ ou para $10 \mathrm{~m}$ ). A orientação da professora possibilita aos alunos, ao construir uma representação do objeto real em um tamanho reduzido, definir variáveis matemáticas e trabalhar com escala e proporção. $O$ procedimento de calcular medidas proporcionais, de $2 \mathrm{~cm}$ para representar $1 \mathrm{~m}$, indica que os alunos utilizaram operações e conhecimentos matemáticos para inferir acerca dos resultados.

Mesmo com os tamanhos que seriam utilizados para a escala sendo definidos é a representação dos silos que leva os alunos a interpretar o material construído em linguagem matemática. Esse fato aparece no Episódio 19.

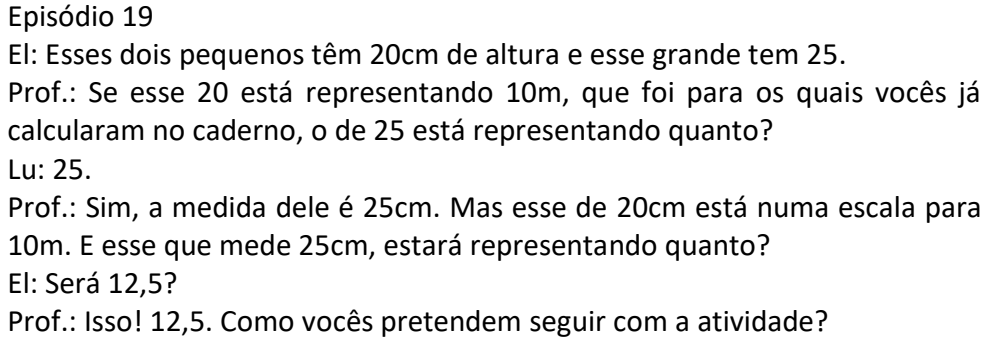

O procedimento dos alunos, identificado nesse Episódio, de realizar uma leitura da atividade desenvolvida quando interpretam que se $20 \mathrm{~cm}$ representa $10 \mathrm{~m}$, logo $25 \mathrm{~cm}$ representaria $12,5 \mathrm{~m}$, oportunizou, nesse processo avaliativo, examinar e explicar as características matemáticas do material construído. Ao considerar a medida de $12,5 \mathrm{~m}$ de altura para o silo os alunos demonstram curiosidade e autonomia para assumir novas possibilidades de investigação. 0 procedimento de perceber que a altura também pode variar pode ter sido decorrente do olhar do aluno sob outras perspectivas matemáticas para resolver o problema.

A partir da percepção de que o volume dependia tanto do tamanho do raio quanto da medida da altura, os alunos passam a tecer novos pensamentos e evidenciam a necessidade de comparar o volume de armazenamento em duas situações distintas: aumento da altura do silo com raio fixo e aumento do raio do silo com altura fixa. Para isso, a professora sugeriu que eles construíssem tabelas, 
como era seu propósito no início da atividade, uma que apresentasse o tamanho do raio variável e a altura fixa e vice versa.

Assim, os procedimentos dos alunos foram de atribuir valores para variáveis e realizar operações matemáticas ao resolver o cálculo de volume do cilindro e de capacidade do silo. Os resultados foram organizados conforme Tabelas 3 e 4.

Tabela 3 - Variação do volume de silo cilíndrico de altura 10m e raio $r$

$\begin{array}{cccccc}\text { Silo } & \text { Raio }(\mathbf{m}) & \mathbf{P i} & \text { Altura }(\mathbf{m}) & \text { Volume }\left(\mathbf{m}^{\mathbf{3}}\right) & \begin{array}{c}\text { Volume } \\ \text { (toneladas) }\end{array} \\ 1 & 2 & 3,14 & 10 & 125,6 & 94,2 \\ 2 & 3 & 3,14 & 10 & 282,6 & 211,95 \\ 3 & 4 & 3,14 & 10 & 502,4 & 376,8 \\ 4 & 5 & 3,14 & 10 & 785 & 588,75\end{array}$

Fonte: Casto (2017).

Tabela 4 - Variação do volume de silo cilíndrico de raio $4 \mathrm{~m}$ e altura $\mathrm{h}$

$\begin{array}{cccccc}\text { Silo } & \text { Raio }(\mathbf{m}) & \mathbf{P i} & \text { Altura }(\mathrm{m}) & \text { Volume }\left(\mathrm{m}^{\mathbf{3}}\right) & \begin{array}{c}\text { Volume } \\ \text { (toneladas) }\end{array} \\ 1 & 4 & 3,14 & 7 & 351,68 & 263,76 \\ 2 & 4 & 3,14 & 8 & 401,92 & 301,44 \\ 3 & 4 & 3,14 & 9 & 452,16 & 339,12 \\ 4 & 4 & 3,14 & 10 & 502,4 & 376,8\end{array}$

Fonte: Casto (2017).

O procedimento de organizar os dados em tabelas de forma a apresentar os resultados viabilizou aos alunos visualizar resultados e realizar comparações plausíveis tanto do volume do silo em função do tamanho do raio e/ou da altura, quanto a variação da capacidade de armazenamento de milho, que era de 0,75 ton $/ \mathrm{m}^{3}$, para os silos estudados. As conclusões dos alunos acerca dos resultados obtidos aparecem no Episódio 20, que retrata o modo como os alunos compreenderam e resolveram o problema em questão.

\footnotetext{
Episódio 20

Prof.: Vocês saberiam explicar como fizeram para calcular o volume de armazenamento?

El: Sim. A gente multiplicou o volume do silo por 0,75 ton $/ \mathrm{m}^{3}$.

Prof.: E como vocês calcularam o volume do silo?

El: Usando a fórmula $v=\pi . r^{2} . h$ e agora "vezes" $0,75$.

Prof.: E o que é $r$, o que é o h e o que é e quanto vale o $\pi$ ? Lu: O ré o raio né? E h é altura.

El: O pi a gente usou 3,14.

Prof.: Isso aí. Quando vocês aumentaram $m$ de raio do silo, quanto que aumentou o armazenamento de milho?

Al: Deixa eu pegar a calculadora.

El: Faça lá: 211,95 menos 94,2 dá igual a... 117,75.

Prof.: E quando aumenta $1 \mathrm{~m}$ de altura?

Prof.: Quando que o aumento no armazenamento é maior: quando aumenta
} 
Neste diálogo a professora interroga a maneira como os alunos descrevem a solução encontrada e representada na tabela, sendo possível perceber que a capacidade de armazenamento de milho de um silo cilíndrico foi calculado por meio da utilização da fórmula $v=\pi \cdot r^{2} \cdot h \cdot 0,75$, em que os alunos obtém a quantidade em toneladas. A partir da análise das respostas e de intervenções da professora, os alunos verificam que ao aumentar em $1 \mathrm{~m}$ o tamanho do raio o volume aumenta em uma proporção maior se comparado ao volume obtido quando a altura aumenta $1 \mathrm{~m}$, ao mesmo tempo em que ressalta que a afirmação realizada é sobre a "primeira 'conta' que a gente fez". Assim, nesse episódio, os procedimentos manifestos pelos alunos foram de analisar a forma como a resposta foi construída, explicar e verificar os métodos que eles utilizaram para chegar aos resultados expressos na tabela, bem como realizar comparações e conclusões acerca do contexto estudado.

Para finalizar, os alunos realizaram uma breve apresentação do trabalho para a professora e para os demais colegas da turma, expondo a construção dos silos em tamanho menor, o cálculo do volume do silo e a capacidade de armazenamento de milho, juntamente com as demais informações extra matemáticas encontradas sobre o tema escolhido em cartazes elaborados para essa finalidade. Dessa forma, expor o material construído, realizar a apresentação oral e em forma de cartazes das informações encontradas e apresentar os resultados matemáticos inferidos se constituem procedimentos dos alunos nesse momento da atividade. Foram esses procedimentos que favoreceram a aceitação da resposta obtida e posterior comunicação de informações e explanação de resultados.

\section{O QUE REVELAM OS PROCEDIMENTOS DOS ALUNOS EM ATIVIDADES DE MODELAGEM MATEMÁTICA}

Em busca de dar um olhar global sobre os procedimentos manifestos pelos alunos de um $8^{\circ}$ ano do Ensino Fundamental ao longo do desenvolvimento das atividades de modelagem matemáticas trazidas nesse estudo, recordamos aspectos dessas atividades, bem como os procedimentos identificados nas três atividades de modelagem abordadas.

Nessas três atividades de modelagem há diversos procedimentos manifestos pelos alunos como selecionar problemas, interpretar dados matemáticos referentes à situação em estudo, discutir estratégias para resolver o problema identificado, apresentar resultados por meio de cartazes, que aparecem na atividade da Erva-Mate; pesquisar sobre o tema, efetuar cálculos com o uso calculadora, analisar os resultados obtidos, que surgem na atividade dos Planetas do Sistema Solar e; optar por ater-se a dados matemáticos, resolver algoritmos matemáticos, perceber novas possibilidades de investigação e obter resultados matemáticos, que acontecem na atividade do Milho. Também nessas atividades há procedimentos que se repetem ou que são muito parecidos, muito embora elas abordam temáticas distintas e tenham características particulares. 
Dentre os que se repetem estão os procedimentos de elaborar perguntas diversas sobre os temas de investigação, estruturar/formular um problema a resolver, elaborar tabelas para organizar os resultados, utilizar operações matemáticas para obter resultados, analisar, comparar respostas e argumentar sobre as soluções encontradas. Já os que são bastante parecidos acontecem, por exemplo, na atividade com o tema Planetas do Sistema Solar quando os alunos buscam por formular um problema e na atividade com a temática Milho ao selecionar o objeto de estudo. Em ambas as atividades os alunos acabam por optar por questões a investigar que julgam mais fáceis, sugerindo assim um procedimento que depõem a escolha de estratégias. Mesmo parecendo ser o mesmo procedimento, ele retrata coisas distintas, ou seja, ele tem significado diferente se considerado o contexto no qual ele foi identificado.

Isso também acontece com o procedimento de comparar resultados, que aparece tanto como processo avaliativo, na atividade do Milho quando os alunos comparam os resultados expressos nas Tabelas 3 e 4 com a intenção de avaliar os resultados obtidos; quanto como procedimento que revela o uso ou compreensão de conceitos matemáticos, no contexto da atividade do grupo da Erva-Mate quando os alunos estão em processo de compreensão de estratégias matemáticas utilizadas.

Outro exemplo de um mesmo procedimento, em diferentes atividades de modelagem, retratar coisas distintas, é o de realizar pesquisa sobre o tema, na atividade dos Planetas do Sistema Solar, que é um procedimento que focaliza a temática em estudo e, o de pesquisar termos, informações e conceitos matemáticos, na atividade do Milho, sugere ser um procedimento que indica organização do trabalho a ser realizado.

Assim, ao olharmos para todos os procedimentos manifestos pelos alunos, nas três atividades abordadas, consideradas as características de uma atividade de modelagem matemática, os organizamos em cinco categorias, a saber: procedimentos que focalizam a temática em estudo, procedimentos que indicam organização do trabalho a ser realizado, procedimentos que depõem a escolha de estratégias, procedimentos que revelam o uso ou compreensão de conceitos matemáticos e procedimentos que denotam processos avaliativos. Essas categorias foram construídas a partir de núcleos de significado por nós identificados, ou seja, o agrupamento se deu a partir da evidência de procedimentos dos alunos que expressam características comuns sob determinado aspecto. No Quadro 5 apresentamos essas categorias associadas aos procedimentos manifestos pelos alunos. 
Quadro 5 - Categorias associadas aos procedimentos dos alunos

\begin{tabular}{|c|c|}
\hline Categorias & Procedimentos manifestos pelos alunos \\
\hline $\begin{array}{l}\text { Procedimentos que } \\
\text { focalizam a } \\
\text { temática em estudo }\end{array}$ & $\begin{array}{c}\text { - Elaborar perguntas sobre o tema. } \\
\text { - Discutir sobre a pergunta a ser elaborada. } \\
\text { - Realizar pesquisa sobre o tema. } \\
\text { - Levantar informações. } \\
\text { - Interpretar problema em linguagem matemática. } \\
\text { - Examinar e explicar características matemáticas do objeto em } \\
\text { estudo. } \\
\text { - Olhar para a resposta obtida. } \\
\text { - Aceitar os resultados como corretos. } \\
\text { - Comunicar a solução encontrada. } \\
\text { - Realizar conclusões sobre os resultados. } \\
\text { - Verificar e explicar os métodos utilizados. } \\
\text { - Argumentar sobre os resultados obtidos. } \\
\text { - Realizar argumentações sobre os encaminhamentos assumidos. }\end{array}$ \\
\hline $\begin{array}{c}\text { Procedimentos que } \\
\text { indicam organização } \\
\text { do trabalho a ser } \\
\text { realizado }\end{array}$ & $\begin{array}{c}\text { - Resumir informações. } \\
\text { - Organizar ideias de investigação. } \\
\text { - Escrever questões direcionadas. } \\
\text { - Formular problemas. } \\
\text { - Estruturar situação problema. } \\
\text { - Reescrever situação problema. } \\
\text { - Pesquisar termos, informações e conceitos matemáticos. } \\
\text { - Reduzir opções de investigação. } \\
\text { - Limitar a busca. } \\
\text { - Direcionar o problema de investigação. }\end{array}$ \\
\hline $\begin{array}{l}\text { Procedimentos que } \\
\text { depõem a escolha } \\
\text { de estratégias }\end{array}$ & $\begin{array}{c}\text { - Buscar por fórmula matemática para resolver o problema. } \\
\text { - Reutilizar seus cálculos para traçar novas estratégias. } \\
\text { - Retomar valores. } \\
\text { - Testar outros valores. } \\
\text { - Ater-se a dados matemáticos. } \\
\text { estudadas. } \\
\text { - Selecionar situações mais próximas da realidade para serem } \\
\text { - Optar pelas situações que julgam mais fáceis. } \\
\text { - Definir a grandeza matemática que sofreria alteração. } \\
\text { - Realizar novo cálculo. } \\
\text { - Construir material. } \\
\text { - Buscar novas perspectivas de trabalho. } \\
\text { - Atribuir valores para variáveis. } \\
\text { - Organizar os resultados em tabelas. } \\
\text { - Expor suas conclusões a partir do material construído. } \\
\text { - Deliberar sobre o problema em seus aspectos matemáticos. } \\
\text { - Optar pelo aspecto mais fácil. } \\
\text { - Definir novos encaminhamentos para o problema. } \\
\text { - Expor sua investigação usando maquete. }\end{array}$ \\
\hline $\begin{array}{l}\text { Procedimentos que } \\
\text { revelam o uso ou } \\
\text { compreensão de } \\
\text { conceitos } \\
\text { matemáticos }\end{array}$ & $\begin{array}{c}\text { - Construir uma representação algébrica para resolver o } \\
\text { problema matemático. } \\
\text { - Compreender processos matemáticos envolvidos. } \\
\text { - Mobilizar conhecimentos prévios. } \\
\text { - Aprender conceitos, técnicas e representações matemáticas. } \\
\text { - Manipular algoritmos matemáticos. } \\
\text { - Comparar resultados. } \\
\text { - Refazer operações. }\end{array}$ \\
\hline
\end{tabular}


Os procedimentos que focalizam a temática em estudo congregam aqueles que consideram aspectos do tema de forma mais ampla. Procedimentos com essa característica denotam a busca por compreender características relacionadas à temática estudada. Os procedimentos que indicam organização do trabalho a ser realizado, remetem ao agir relacionado à simplificação, delimitação e direcionamento do estudo, ao passo que se busca organizar dados, informações, resultados. Já os procedimentos que depõem a escolha de estratégias, de modo geral, relacionam-se ao modo como os alunos buscam solucionar o problema em foco e aos métodos/recursos pensados ou utilizados no processo de busca pela resposta. Procedimentos que revelam o uso ou compreensão de conceitos matemáticos associam-se àqueles que consideram os conhecimentos matemáticos dos alunos empregados durante o desenvolvimento da atividade ou entendimento e interpretação de conceitos matemáticos empreendidos na resolução do problema matemático contextualizado à situação. E, por fim, procedimentos que denotam processos avaliativos aglutinam aqueles que se pautam na análise, interpretação e validação dos resultados encontrados/construídos na aceitação de uma resposta para o problema em estudo.

Nessa categorização evidenciamos que em uma mesma categoria há procedimentos que são matemáticos e procedimentos não matemáticos, sinalizando que no desenvolvimento de uma atividade de modelagem matemática emerge, a todo o momento, tanto conhecimentos matemáticos como não matemáticos. Como exemplo, na categoria dos procedimentos que depõem escolha de estratégias, aparecem procedimentos matemáticos (reutilizar seus 
cálculos para traçar novas estratégias, atribuir valores para variáveis e testar outros valores são procedimentos matemáticos) e procedimentos não matemáticos (apresentar os resultados por meio de cartazes e selecionar situações mais próximas da realidade para serem estudadas).

Além disso, os procedimentos matemáticos não necessariamente aparecem associados à categoria dos procedimentos que revelam o uso ou compreensão de conceitos matemáticos. Tal inferência pode ser constatada quando identificamos que os procedimentos testar outros valores (atividade Erva-Mate), ater-se a dados matemáticos e realizar novo cálculo (estes na atividade Milho), considerando-se o contexto que foram evidenciados, associam-se à categoria que depõem a escolha de estratégias.

A análise realizada também nos leva a comunicar que os procedimentos que depõem escolhas de estratégias, de modo geral, são os que mais influenciam no desenvolvimento da atividade de modelagem matemática, ou seja, é nessa categoria que se mostram os procedimentos mais decisivos nas atividades analisadas. Na atividade com o tema Milho, um procedimento com essa característica, pode ser identificado quando os alunos optam pelo estudo do silo em formato cilíndrico, por ser mais próximo da sua realidade, e ao definirem um valor fixo para a altura do silo, optando por variar o tamanho do raio, isto é, a variável a ser alterada.

Da análise constatamos também que muitos procedimentos manifestos pelos alunos precisaram ser revistos, corrigidos e/ou reestruturados, o que acarretou na manifestação de novos procedimentos, ou seja, quando algum procedimento não satisfez ou não contribuiu para o "bom" desenvolvimento da atividade de modelagem houve a retomada desses procedimentos, retificando-os quando possível ou levando à manifestação de novos. Como exemplo, na atividade com o tema Erva-Mate, o procedimento de verificar a resposta como não válida para aquela circunstância, fez emergir o procedimento de rever fórmulas e conceitos e, assim, houve a manifestação de outro procedimento: de repensar os cálculos e valores envolvidos.

Assim, os procedimentos manifestos pelos alunos, em cada uma das atividades de modelagem matemática analisadas, ora levam os alunos a explicitar, alterar e/ou modificar seus modos de pensar, ao passo que exige deles a mobilização e/ou construção de conhecimentos matemáticos ou não, ora os provocam a rever seus pensamentos e suas decisões. Ainda, na transição da situação inicial para a situação final em uma atividade de modelagem matemática, observamos que não é apenas um procedimento isolado, mas o conjunto de procedimentos manifestos pelos alunos que contribui para que conhecimentos matemáticos e não matemáticos sejam mobilizados e/ou construídos e integrados.

Desse fato, inferimos que os procedimentos aparecem interligados, dependentes um do outro e se completam ao longo da atividade, ou seja, os procedimentos se complementam na medida em que os alunos buscam responder ao problema que originou a atividade de modelagem matemática.

\section{CONSIDERAÇÕES FINAIS} ano do Ensino Fundamental e que sustentam as discussões e reflexões 
apresentadas neste estudo tiveram seus temas escolhidos segundo os interesses dos grupos de alunos que as desenvolveram. Sendo assim, características peculiares da Modelagem Matemática foram trazidas à tona ao passo que os alunos tiveram oportunidade de aprender ou revisitar conceitos matemáticos tendo aspectos da realidade como ponto de partida.

Foi ao longo do desenvolvimento das três atividades de modelagem matemática abordadas, Erva-Mate, Planetas do Sistema Solar e Milho, que procedimentos foram manifestos e, neste estudo, assumidos como objeto de análise.

Ao olhar para os procedimentos manifestos pelos alunos ao longo do desenvolvimento dessas atividades de modelagem constatamos que eles constituem blocos de procedimentos, que foram organizados em cinco categorias. Também ponderamos que todos os procedimentos manifestos em cada uma das atividades de modelagem são determinantes para a elaboração de uma resposta para o problema que as originaram, sejam eles matemáticos ou não matemáticos.

Sendo assim, mais do que aprender matemática, atividades de modelagem matemática possibilitam conhecimentos diversos. Também, sugerem um olhar para a matemática de forma ampla, uma vez que os conceitos trabalhados, utilizados e discutidos no âmbito de uma atividade de modelagem matemática vêm aliados ao olhar que setenta ou se pretende dar ao problema em estudo. 0 olhar sobre a situação e o encaminhamento dado à atividade completa-se na interação e cooperação possibilitada pelo trabalho em grupo, bem como pela mediação do professor.

Embora foge ao escopo desse estudo discutir acerca do professor no desenvolvimento de atividades de modelagem matemática, entendemos que é relevante sua influência na forma como o aluno percebe, vivencia e desenvolve uma atividade de modelagem. Por isso, nos Episódios também trazemos as falas da professora e, sendo assim, consideramos que os procedimentos dos alunos não podem ser analisados separadamente, ou seja, precisam ser compreendidos em um contexto que considera as interações entre os alunos do grupo e as intervenções do professor.

A dinâmica de discussão instaurada nos três grupos revelou que os procedimentos manifestos pelos alunos acontecem a partir de um movimento de idas e vindas na atividade de modelagem provocado devido eles retomarem ou repensarem sobre aspectos já considerados e da avaliação deles quando julgado necessário.

Praticamente nas três atividades de modelagem os procedimentos manifestos pelos alunos precisaram, em momento posterior, serem revistos. Isso denota, que mesmo os procedimentos sendo resultado da forma como os alunos pensaram, eles não os avaliam imediatamente à sua manifestação. Além disso, os alunos nem sempre percebem a necessidade de rever informações ou soluções não válidas, resultando que alguns procedimentos se repetem ao longo da atividade de modelagem matemática. Porém, mesmos os procedimentos sendo iguais ou pareçam semelhantes, identificamos que eles carregam características do contexto em que emergem e, nesse sentido, têm significados diferentes.

Outra constatação é que procedimentos matemáticos e não matemáticos aparecem em todas as categorias identificadas, sugerindo que conhecimentos 
matemáticos e conhecimentos acerca da situação em estudo são acionados durante todo o desenvolvimento das atividades de modelagem matemática.

Convém destacar que as atividades de modelagem matemática descritas neste estudo representam apenas uma das possibilidades de se abordar o tema Erva-Mate, Milho e Planetas do Sistema Solar. Foi o olhar peculiar dos alunos, reunidos em grupos, e as intervenções do professor, que os levou a manifestar procedimentos que se mostraram relacionados ao seu modo de pensar, entender e administrar as informações sobre o tema e sobre matemática, e que se permitiram o desenvolvimento ora relatado e discutido. 


\title{
PROCEDURES MANIFESTED BY STUDENTS IN MATHEMATICAL MODELING ACTIVITIES: UNDERSTANDINGS IN THE LIGHT OF CONTENT ANALYSIS
}

\begin{abstract}
In this work, we bring into discussion the procedures manifested by students of an 8th year of the Elementary School when developing mathematical modeling activities. To discuss this procedures we present some episodes that portray the dynamics of their involvement with modeling activities, supported by Content Analysis, as proposed by Laurence Bardin. From the analysis, we identified five categories of procedures: focus on the subject being studied, indicate the organization of the work to be performed, determine the choice of strategies, reveal the use or understanding of mathematical concepts and denote evaluation processes. We concluded that in mathematical modeling activities, the procedures manifested by the students cannot be analyzed in isolation; it is the set of procedures in their totality, that allow the development of the mathematical modeling activity and that implicitly or explicitly carry: the students' intentions and knowledge, their own negotiations or the ones carried out between them and the teacher.
\end{abstract}

KEYWORDS: Mathematical modeling activities. Students' procedures. Content analysis. 


\section{REFERÊNCIAS}

ALMEIDA, L. M. W.; BRITO, D. S. Atividades de Modelagem Matemática: que sentido os alunos podem lhe atribuir? Ciência \& Educação, Bauru, v.11, n.3, p.483-497, 2005.

ALMEIDA, L. W. de; SILVA, K. P.; VERTUAN, R. E. Modelagem Matemática na Educação Básica. 1.ed. 1arreimpressão. SP: Contexto, 2013.

BARDIN, L. Análise de conteúdo. Lisboa: Edições 70 Ltda, 1977.

CASTRO, É. M. V.. Procedimentos dos alunos associados às suas ações cognitivas em atividades de modelagem matemática. Dissertação - Universidade Estadual do Centro-Oeste, Programa de Pós-Graduação em Ensino de Ciências Naturais e Matemática. Guarapuava, 2017.

LÜDKE, M.; ANDRÉ, M. E. D. Pesquisa em educação: abordagens qualitativas. 10.reimp. SP: EPU, 2007.

VERONEZ, M. R. D. As funções dos signos em atividades de modelagem matemática. 2013. 176p. Tese de Doutorado (Pós-Graduação em Ensino de Ciências e Educação Matemática) - Universidade Estadual de Londrina, Londrina, 2013.

VERTUAN, R.E. Práticas de Monitoramento Cognitivo em Atividades de Modelagem Matemática. 247p. Tese de Doutorado (Pós Graduação em Ensino de Ciências e Educação Matemática) - Universidade Estadual de Londrina, Londrina, 2013. 
Recebido: 05 fev. 2019

Aprovado: 14 out. 2019

DOI: $10.3895 /$ rbect.v13n2.9538

Como citar: CASTRO, E. M. V.; VERONEZ, M. R. D. Procedimentos manifestos por alunos em atividades de

modelagem matemática: compreensões à luz da análise de conteúdo. Revista Brasileira de Ensino de

Ciência e Tecnologia, Ponta Grossa, v.13, n. 2, p. 287-319, mai./ago. 2020. Disponível em:

$<$ https://periodicos. utfpr.edu.br/rbect/article/view/9538>. Acesso em: XXX

Correspondência: Elida Maiara Velozo de Castro - elidamaiara.vc@gmail.com

Direito autoral: Este artigo está licenciado sob os termos da Licença Creative Commons-Atribuição 4.0

Internacional.

\section{(c) (1)}

